D:INsurg|Vol. 24, No. 1, Jan. - Mar., 2020\Nsurg-11.Doc $\quad$ P. $73-76 \quad$ III

ORIGINAL ARTICLE

\title{
Anterior Cervical Discectomy and Fusion: Operative Technique and Post-Operative Complications - An Experience in a Tertiary Care Hospital
}

\author{
MUHAMMAD AKMAL, OMAIR AFZAL, ADEEB-UL-HASSAN \\ MUHAMMAD HASSAN RAZA, MUHAMMAD ISHFAQ, KHALID MAHMOOD \\ Punjab Institute of Neurosciences (PINS), Lahore - Pakistan
}

DOI: $10.36552 /$ pjns.v24i1.377

ABSTRACT

Background and Objective: The most common spinal procedure in our set up to address various disorders of the cervical spine like prolapsed intervertebral disc, trauma, and degenerative disc disease is an anterior cervical discectomy and fusion (ACDF). As there is no technique without complication, this procedure is also related with certain important complications. We evaluated post-operative complications of ACDF in our institution.

Material and Methods: The preoperative data of 148 patients who were operated in last 3 years for ACDF is included in the study. Patients with previous neck surgery are excluded.

Results: The most commonly performed surgical interventions is single level ACDF (65\%). Dysphagia is most significant (16\%) complication. After which neurological deterioration (9\%) with equal incidence of Recurrent Laryngeal Nerve Palsy and wound infection that is $8 \%$ each.

Conclusion: The most common post-operative complications are dysphagia and worsening of preexisting neurology and multilevel ACDF is identified as the most common risk factor. Early recognition of complications and management may help to reduce mortality and morbidity.

Keywords: Post-operative complication of ACDF, Radiculopathy, Spondylosis.

\section{INTRODUCTION}

Cervical Radiculopathy is usually caused by pathological involvement of cervical nerve roots as a result of chronic compression and inflammation of nerve roots, at neural foramina. There are two common causes of radiculopathy Cervical Spondylosis and Cervical Disc Herniation. In younger patients radiculopathy is due to herniated disc which results in compression on exiting nerve root, where as in older patient it is due to foraminal narrowing as a result of the osteophytes formation (spondylosis). Also, associated with cervical spondylosis is ossification of the posterior longitudinal ligament (OPLL). It results in a clinically presented anterior compression of the cord, such as cervical spondylotic myelopathy (CSM).

Conservative management includes the use of nonsteroidal anti-inflammatory drugs as a component of pharmacology and rehabilitation, muscle relaxants, analgesics, antidepressants, and cervical steroid injection. Many modalities include physical therapy, collars, cervical traction, heat and acupuncture. Surgery is the cornerstone of CSM therapy. It is suggested for those patients having radiological and clinical indication of myelopathy. The CSM progresses without surgery.

The most common complication of ACDF includes acute airway obstruction to chronic cord dysfunction. ${ }^{1}$ A surgery requiring more than 3 levels of the vertebral bodies or blood loss of $350 \mathrm{ml}$, presents the major risk of airway obstruction.

RLN paralysis is a common otolaryngological complication (4), the dysfunction of the nerve usually resolves within three months.

The other ACDF complications include, 
mechanical instability, vertebral artery tear, carotid artery or jugular vein injury, epidural hematoma formation, pneumothorax, wound infection, Dural laceration, dysphagia, transient or permanent myelopathy, nerve root injury. We carried out this study to know most common post-operative complication after ACDF in our population.

\section{MATERIAL AND METHODS}

\section{Study Design}

Informed consents from 148 patients were taken along with Institutional permission from ethical committee and retrospective study was conducted based on postoperative data over a period of 3 years (Feb. 2015 to Feb. 2018).

\section{Inclusion Criteria}

The study included a total of 148 patients with ACDF from 1 to 3 levels of cervical radiculopathy and/or secondary myelopathy with degenerative disorder.

\section{Exclusion Criteria}

Patients with prior neck surgery are omitted.

\section{Data Collection}

All the data was collected from case records, anesthesia notes and discharge cards. Clinical medical evaluations were done, which were required for follow-up during hospital stay. Preoperative evaluation includes cervical spine X-ray AP, lateral views, CT scan cervical spine with 3D Reconstruction, MRI cervical spine plain, routine blood workup and prothrombin time were obtained.

\section{Surgical Technique}

The Anterior Smith Robinson technique is used. The patient's head is rotated to the left in the supine position. An incision is made along the sternocleidomastoid muscle. The fluoroscope is used to verify the operative level. Annulus is cut, curettes are used to remove degenerative disks and drill end plates. Further dissection is performed laterally. Body decompression both neural foramina and nerve root decompression is ensured.

\section{Data Analysis}

SPSS 20 produces statistical analysis.

\section{RESULTS}

Collective data of 148 patients who had ACDF during the study period.

\section{Gender Incidence}

There were 105 (75\%) Male and 43 (29\%) Females.

\section{Age Incidence}

Their ages ranged between 22 to 80 years.

\section{Clinical Features}

Weakness of the extremities and paraesthesias were the most common presenting complaints (Table 1). Most of the patients had 1 level ACDF (65\%), 41 (28\%) patients had 2 level and $3(2 \%)$ patients had 3 levels ACDF. Fusion in these patients was performed with tricotical iliac crest autologous graft (78\%). Twenty three $(16 \%)$ patients had mild to moderate dysphagia, 1 of these patients had an anterior graft dislocation. Most of these patients (15 of 23) had no problem with drinking; eating and they considered their swallowing difficulty was not significant. Many of these symptoms subsidized in 11 to 15 days. Eight out of 23 reported moderate difficulty swallowing which was progressively reduced over a time of three to four weeks and eventually disappeared with no further consequence. We found that the incidence of dysphagia was increased in patients with three levels as compared to those with one or two levels of ACDF.

Fusion was performed with tricotical iliac crest autologous graft or polyetheretherketone (PEEK) cage.

Table 1: Distribution of Different Presentations.

\begin{tabular}{|l|l|c|}
\hline & Presentation & Numbers of Patient (\%) \\
\hline 1. & Extremity Weakness & $120(81 \%)$ \\
\hline 2. & Paraesthesia & $105(71 \%)$ \\
\hline 3. & Neck pain & $90(61 \%)$ \\
\hline 4. & Stiffness/gait abnormality & $65(44 \%)$ \\
\hline 5. & Radiation of pain & $62(42 \%)$ \\
\hline 6. & Bladder/bowel involvement & $55(37 \%)$ \\
\hline
\end{tabular}

There was neurological deterioration in $13(9 \%)$ of the patients. The patients who were operated for level 1,2 or 3 ACDF did not show significant difference in 
Table 2: Post-Operative Complications.

\begin{tabular}{|c|c|c|c|c|c|c|c|c|}
\hline $\begin{array}{c}\text { Numbers of } \\
\text { Levels }\end{array}$ & $\begin{array}{c}\text { No of } \\
\text { Patients }\end{array}$ & Dysphagia & $\begin{array}{c}\text { Neurological } \\
\text { Deterioration }\end{array}$ & $\begin{array}{c}\text { RLN } \\
\text { Palsy }\end{array}$ & $\begin{array}{c}\text { Dural } \\
\text { Tear }\end{array}$ & $\begin{array}{c}\text { Anti-graft } \\
\text { Dislocation }\end{array}$ & $\begin{array}{c}\text { Esophageal } \\
\text { Perforation }\end{array}$ & $\begin{array}{c}\text { Wound } \\
\text { Infection }\end{array}$ \\
\hline 1 & 96 & 11 & 7 & 8 & 4 & 2 & 0 & 5 \\
\hline 2 & 41 & 9 & 5 & 2 & 1 & 0 & 0 & 2 \\
\hline 3 & 11 & 3 & 1 & 2 & 0 & 0 & 0 & 1 \\
\hline
\end{tabular}

worsening of their pre-operative myelopathy. In 4 (3\%) patients' posterior displacement of bone graft was the cause of worsening quadriparesis. They were given intravenous methylprednisolone sodium succinate. The re-exploration was performed and previous graft was replaced. These patients returned to their pre-operative status in 6 months. Three $3(2 \%)$ patients had temporary Para paresis. Our $12(8 \%)$ patients developed unilateral Recurrent Laryngeal Nerve (RLN) palsy, they were diagnosed by indirect laryngoscopy and managed conservatively. These patients completely recovered over a period of 2 months. There was no association of number of ACDF levels with RNL palsy post operatively.

Five $(3.3 \%)$ patients developed post-operative CSF leak, which we managed successfully with lumbar drain and application of tension sutures with proline, all patients recovered well.

Anterior graft dislocation was diagnosed in 2 (1.3\%) patients. One patient had post-operative Dysphagia second patient was asymptomatic; both patients were subjected to re-exploration and iliac crest bone graft fusion.

An alarming post-operative complication in our study was wound infection, $8(5 \%)$ patient had it and these patients recovered completely after administration of systemic antibiotics.

\section{DISCUSSION}

ACDF is one of the most commonly performed cervical spinal procedure. This procedure carries an excellent clinical outcome in most of the cases. Occasionally some serious complications also been reported. ${ }^{1}$ Surgical traction of neck tissues and irritation after intubation may lead to mild transient Dysphagia. $^{2}$ Rarely, post-operative hematoma, esophageal injury and anterior graft dislocation leads to Dysphagia, but exact mechanism and the pathophysiology is unknown. Dysphagia is our study's most severe $(16 \%)$ postoperative complication. In a patient, the soft tissue retraction \& rough wild dissection underwent 3 level ACDF shows a higher rate of dysphagia than in other cases. In other clinical studies, the incidence of dysphagia ranges from 2 to 67 percent. Multilevel surgery and female sex were identified by as risk factors for dysphagia development.

During general anesthesia keeping of ETT cuff pressure amid 15 to $25 \mathrm{~mm} \mathrm{Hg}$ may reduce intubation related complications in ACDF. Hoarseness, Sore throat and dysphagia may be reduced after lowering the endotracheal tube cuff pressure during ACDF after placement of the retractors.

Spinal cord contusions and graft dislocations lead to neurological deterioration in $13(9 \%)$ of the patients. Eggert et al. stated deteriorating of preexisting myelopathy in $3.4 \%$ of patients.

The documented occurrence of recurrent laryngeal nerve palsy identified as heaviness, vocal exhaustion, postoperative airway obstruction of persistent cough and dysphagia during $\mathrm{ACDF}$ ranged from $0.2 \%$ to $16.7 \% .^{6}$

In our study, $12(8 \%)$ patients developed unilateral RLN paralysis, their incidence is higher than that stated by Fountas et al, who detected this complication in $3.2 \%$ of their patients. Overall, Jung et al established 24 percent after ACDF. ${ }^{5}$

In our study, sample, 3.3 percent of patients report dural tears and CSF leak. It is stated that the dural perforations range from 0.2 to $2.8 \%$. In 1.8 percent of his patients, Eggert observed dural perforation. In our study, we found a slightly higher incidence of CSF leakage.

Pharyngeal and esophageal perforations are dreaded complications of ACDF surgery. It is not clear the precise incidence. Postoperative hematoma at the wound site accounts for 1 to 10 percent of the complication. No such complication has been experienced by our clinicians. Decreased retraction of the tissue can stop the development of a hematoma.

There are certain limitations to this study as we have not performed intraoperative neurophysiological 
monitoring the use of motor evoked potentials and somatosensory evoked potentials may help to reduce intraoperative spinal cord injury. Furthermore, detailed graft related complications are not evaluated.

\section{CONCLUSION}

ACDF is the therapy of choice for secondary to anterior compression cervical myelopathy or radiculopathy following osteophytes and disk prolapse. The most common cause of acute airway obstruction is laryngeal or pharyngeal edema.

The following are the most common complications after ACDF are deterioration of preexisting Myelopathy, Swallowing difficulty, Wound infection, RLN palsy. Multiple levels ACDF are the main risk for post-operative dysphagia.

\section{REFERENCES}

1. Bertalanffy H, Eggert HR. Complications of anterior cervicaldiscectomy without fusion in 450 consecutive patients. Acta Neurotic (Wien), 1989; 99: 41-50.

2. Riley LH 3rd, Vaccaro AR, Dettori JR, Hashimoto R.Postoperative dysphagia in anterior cervical spine surgery. Spine (Phila Pa 1976) 2010; 359 Suppl: S7685.

3. Hunt WE, Miller CA. Management of cervical radiculopathy. Clin Neurosurg. 1986; 33: 485-502.

4. Emery SE. Cervical spondylotic myelopathy: Diagnosis andtreatment. J Am Acad Orthop Surg 2001; 9: 376-88.

5. Fountas KN, Kapsalaki EZ, Nikolakakos LG, Smisson $\mathrm{HF}$, Johnston KW, Grigorian AA, et al. Anterior cervical discectomyand fusion associated complications. Spine (Phila Pa 1976), 2007; 32: 2310-7.

6. Sagi HC, Beutler W, Carroll E, Connolly PJ. Airwaycomplications associated with surgery on the anterior cervicalspine. Spine (Phila Pa 1976), 2002; 27: 949-53.

7. Li F, Gorji R, Allott G, Modes K, Lunn R, Yang ZJ. The usefulnessof intraoperative neurophysiological monitoring in cervicalspine surgery: A retrospective analysis of 200 consecutivepatients. J Neurosurg Anesthesiol. 2012; 24: 185-90.

8. Ferrante FM, Wilson SP, Iacobo C, Orav EJ, Rocco AG, Lipson S.Clinical classification as a predictor of therapeutic outcomeafter cervical epidural steroid injection. Spine (Phila Pa 1976), 1993; 18: 730-6.

9. Rowlingson JC, Kirschenbaum LP. Epidural analgesic techniques in the management of cervical pain. Anesth Analg. 1986; 65: 938-42.

\section{Additional Information}

Disclosures: Authors report no conflict of interest.

Ethical Review Board Approval: The study was conformed to the ethical review board requirements.

Human Subjects: Consent was obtained by all patients/participants in this study.

Conflicts of Interest: In compliance with the ICMJE uniform disclosure form, all authors declare the following.

Financial Relationships: All authors have declared that they have no financial relationships at present or within the previous three years with any organizations that might have an interest in the submitted work.

Other Relationships: All authors have declared that there are no other relationships or activities that could appear to have influenced the submitted work.

Address for Correspondence: Dr. Adeeb-ul-Hassan Punjab Institute of Neurosciences (PINS), Lahore-Pakistan. Email: pinslgh@gmail.com

\begin{tabular}{|l|l|l|l|}
\hline \multicolumn{4}{|c|}{ AUTHORSHIP AND CONTRIBUTION DECLARATION } \\
\hline Sr.\# & Author's Full Name & Intellectual/Contribution to Paper in Terms of: & Signature by the \\
author(s)
\end{tabular}

Date of Submission: 02-12-2019

Date of Revision: 10-03-2020
Date of Online Publishing: 25-03-2020

Date of Print: 31-03-2020 